\begin{tabular}{c} 
International Journal of Engineering \& Technology, $7(3.31)(2018) 40-44$ \\
International Journal of Engineering \& Technology \\
Website: www.sciencepubco.com/index.php/IJET \\
Research paper \\
\hline
\end{tabular}

\title{
Performance Improvement of Sri Yantra Shaped Multiband Antenna with Defected Ground Structure
}

\author{
P. Krishna Kanth Varma*, Ch. Murali Krishna, G. Santhi Ratna Priyanka \\ Department of Electronics and Communication Engineering, SRKR Engineering College, Andhra Pradesh, India- \\ 534204 \\ *Corresponding author E-mail:varmakk.pen2@gmail.com
}

\begin{abstract}
A hybrid fractal antenna inspired from sri yantra geometry covering multiple bands in the microwave frequency spectrum is presented in this paper with a reduced size of $45 \mathrm{~mm} \times 30 \mathrm{~mm} \times 1.6 \mathrm{~mm}$. The presented design aims at a multiband antenna with a polygon slots inscribed in a circular patch with defected ground structure and the effect of Sri Yantra fractal iterations on the antenna characteristics are also studied. The gains achieved at respective bands for Sri Yantra geometry are $4.61 \mathrm{~dB}$ at $4.04 \mathrm{GHz}, 2.71 \mathrm{~dB}$ at $4.94 \mathrm{GHz}, 4.77 \mathrm{~dB}$ at $5.88 \mathrm{GHz}, 3.41 \mathrm{~dB}$ at $6.60 \mathrm{GHz}, 5.12 \mathrm{~dB}$ at $7.24 \mathrm{GHz}, 3.11 \mathrm{~dB}$ at $8.88 \mathrm{GHz}$ and $3.47 \mathrm{~dB}$ at $10.92 \mathrm{GHz}$.
\end{abstract}

Keywords: Multiband, Sri-yantra shape, fractal, polygon slot, defected ground.

\section{Introduction}

The present day mobile technology facilitates universal wireless communication access to citizens worldwide with ever evolving features. Since last few decades, rapid development of the communication technology such as cell phone technology, satellite communication for examines and recovering of local information has demanded to operate with dual or multiband characteristics. Ultra wide band (UWB) systems used for short range communications with stable gain. Now, mobile communication system operate at various frequency bands requires a multiband antenna. Recently, compact size antenna design is the main aspect in the wireless communication. Recent demands in antenna design include operability at higher end of the microwave spectrum. The $5 \mathrm{G}$ systems are probable to operate at centimeter and millimeter wave frequency bands, in which there is an unexploited spectrum worldwide.

There are several methods for enhancing the number of characteristics like impedance bandwidth, gain, efficiency, impedance matching of micro strip patch antenna, which includes selfiterating fractal structures, altering(defecting) the ground plane (Defected Ground Structure), employing slots of different shapes on the patch, Substrate Integrated Waveguide (SIW) and optimization techniques. In [1], by introducing the circular and hexagonal ring slots in the bow tie antenna design, the wide band antenna characteristics has been altered to multiple resonances at $2.4 \mathrm{GHz}, 3.5 \mathrm{GHz}$ and $5.3 \mathrm{GHz}$. Fractal shapes implementation on planar antenna geometries for multiband applications is a well perceived notion. A novel implementation of right angled Koch fractal shapes on the edges of a end fed square patch has resulted in six resonances ranging from $4.3 \mathrm{GHz}$ to $9.2 \mathrm{GHz}$ [2]. The fractal Koch shape has further application on dipole structures in order to yield multiband [3]. For various DGS's applied to the H-shaped patch antenna with FR-4 substrate, have also been observed in producing multiple bands at $2.7 \mathrm{GHz}, 4.8 \mathrm{GHz}$ and $6.2 \mathrm{GHz}$ with better gain characteristics [4]. A hybrid fractal monopole antenna has been developed with MIMO system for covering multiband for the handheld mobile device applications [5]. Due to the selfsimilarity, multiband fractal antenna implemented using Coplanar Waveguide (CPW) feed and also circular polarization exhibited [6]. The idea of DGS with a meaningful mathematical modeling for different convention shapes in antenna design is better explained in [7]. New geometries of DGS such as a square slot on a ground plane of CPW feed [8] and a wide U slot design in the partial gournd plane [9] have illustrated the effectiveness of DGS in enhancing multiband operation.

In this paper, an edge fed Sri Yantra circular fractal antenna is presented with iterative rectangular slots in ground. This proposed antenna results multi resonances with good impedance matching and sufficient gains achieved. This paper can be organized into following sections. Section 2 describes about the model designing and parameters listed in tables. Section 3 demonstrates the discussion and results comparison shown in tables. Section 4 explains about the experimental authentication with results. Section 5 discusses about the conclusion and Section 6 about references.

\section{Design Methodology}

The Sri Yantra fractal shape is better implemented on a circular patch with narrow feed with design parameters derived from [1013]. The initial parameters are designed for resonant frequency of 3.2GHz, utilizing an FR-4 epoxy substrate with optimum thickness (h) of $1.6 \mathrm{~mm}$.

\subsection{Sri Yantra construction}

This Sri Yantra design constructed with the nine interlacing 
isosceles triangles, in that four are upwards and remaining are downwards. Finally, they produce 43 subsidiary triangles organized in 5 concentric stages. The two biggest outermost triangles touch the outer circle on the all three points. The construction of sriyantra is more difficult because every triangle is connected to one or more triangles at common points. Figure 1 depicts the properties of sriyantra construction. Mainly, there are three properties for sriyantra design [17].

(i)

i. Concurrency-All the triple intersection of triangles meet at the same point rather than Criss-crossing.

ii. Concentricity- The center of the innermost triangle co- incides with the center of the outer Circle.

iii. Equilateral inner triangle - The central triangle results an equilateral triangle.

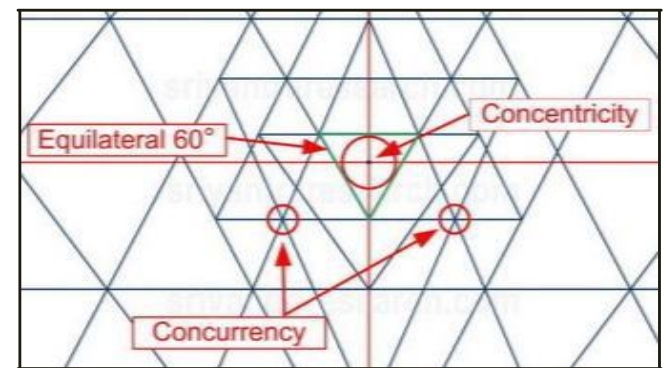

Fig. 1: Properties of sriyantra construction

Figure 2 shows the initial circular patch antenna with parameters. The corresponding simulation results are discussed in section III. All these parameters are listed in Table 1. Further, the circular shape can be modified into Sri Yantra shape in the stand- ard procedures [14-17] with an overall size of $45 \mathrm{~mm} \times$ $30 \mathrm{~mm}$ as shown in Figure 3. Further far field results are improved, by im- plementing iterative rectangular slots and strips in the ground plane. Figure 4 presents the iterative development of the Sri Yan- tra shaped antenna from the circular patch.

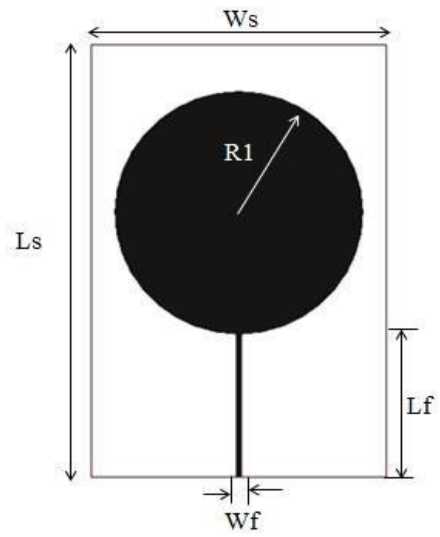

Fig. 2: Circular patch antenna design

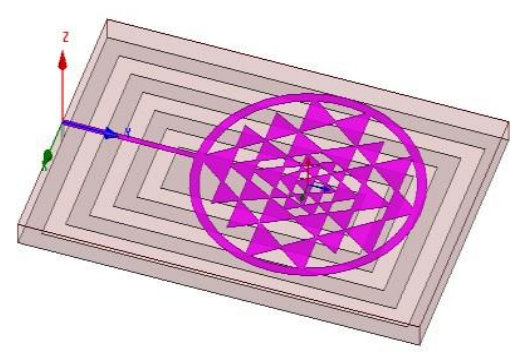

(a)

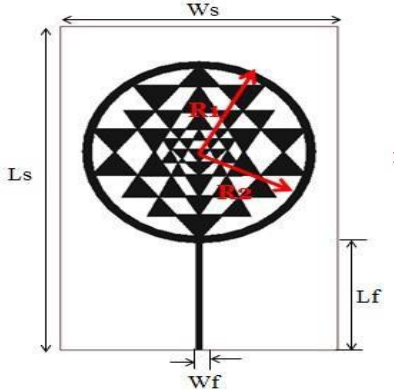

(b)

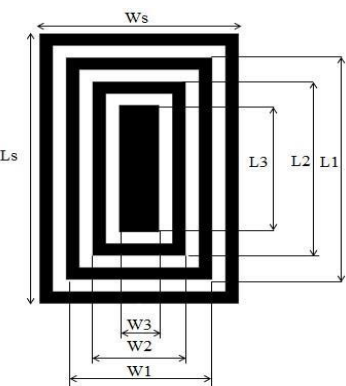

(c)
Fig. 3: a) 3D overall view b) Sri Yantra patch c) Rectangular slot DGS

\begin{tabular}{cccc}
\multicolumn{4}{c}{ Table 1:. } \\
\hline Ls & Ws & Lf & Wf \\
\hline $45 \mathrm{~mm}$ & $30 \mathrm{~mm}$ & $14.896 \mathrm{~mm}$ & $0.6 \mathrm{~mm}$ \\
$\mathrm{~L} 1$ & $\mathrm{~L} 2$ & $\mathrm{~L} 3$ & $\mathrm{~W} 1$ \\
$37 \mathrm{~mm}$ & $29 \mathrm{~mm}$ & $21 \mathrm{~mm}$ & $22 \mathrm{~mm}$ \\
$\mathrm{~W} 2$ & $\mathrm{~W} 3$ & $\mathrm{R} 1$ & $\mathrm{R} 2$ \\
$14 \mathrm{~mm}$ & $6 \mathrm{~mm}$ & $12.62 \mathrm{~mm}$ & $11.62 \mathrm{~mm}$ \\
\hline
\end{tabular}

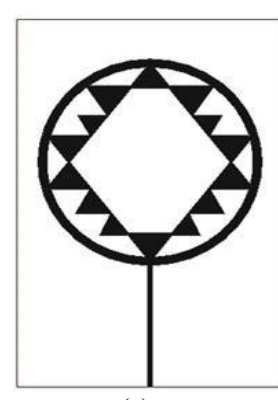

(a)



(c)

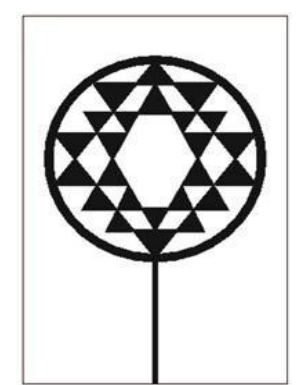

(b)

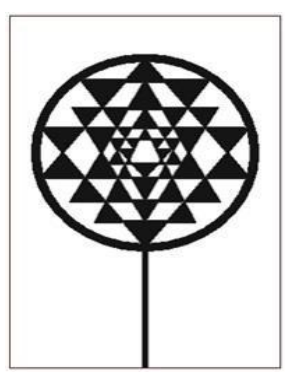

(d)
Fig. 4: Iterative development of the Sri Yantra shaped patch antenna a) First b) Second c) Third d) Fourth e) Fifth (proposed)

\section{Simulation Results \& Discussion}

The proposed iterative fractal structure developed and simulated using HFSS EM simulator. Figure 5 presents the return loss characteristics of the successive five iterations of the antenna design ranging from $1 \mathrm{GHz}$ to $12 \mathrm{GHz}$.

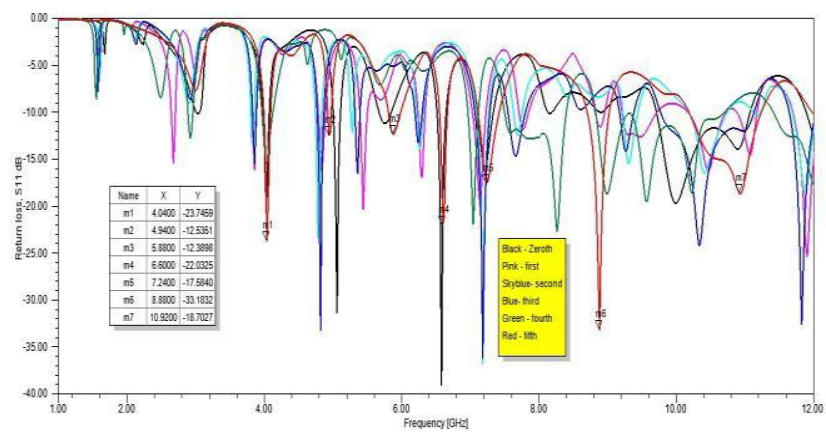

Fig. 5: Comparison of reflection coefficients for various iterations 


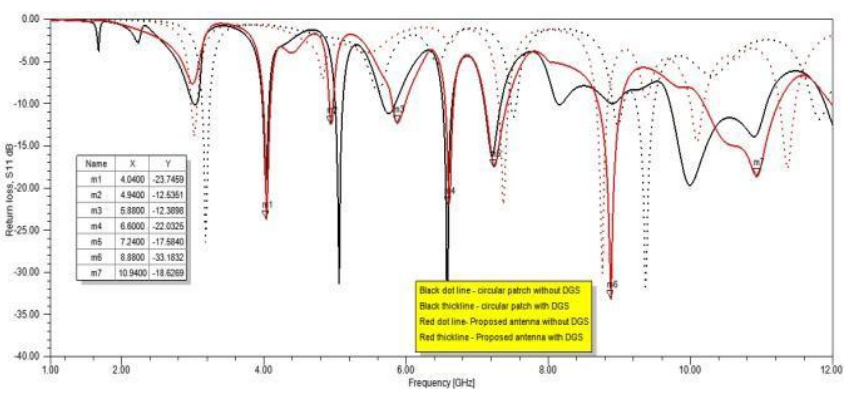

Fig. 6: Return loss comparison of narrow fed circular patch and Sri Yantra patch in presence and absence of DGS

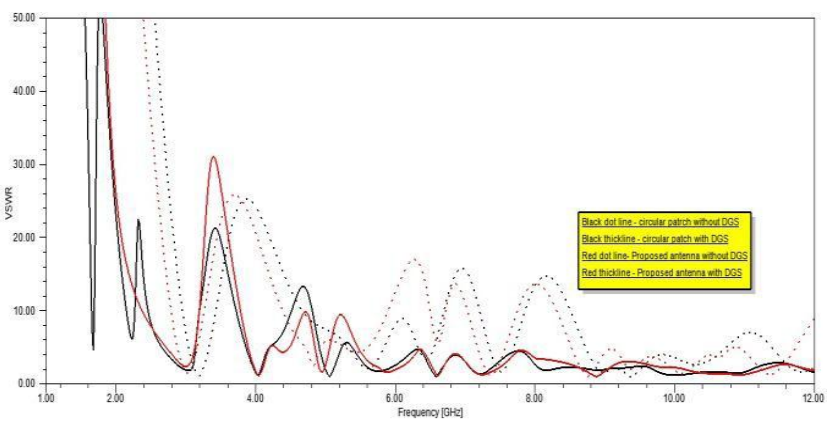

Fig. 7: VSWR comparison of narrow fed circular patch and Sri Yantra patch in presence and absence of DGS

Figure 6 demonstrates the return loss comparison of narrow fed circular patch and Sri Yantra antenna with and without DGS. After several optimizations, three concentric rings introduced in the full ground with constant width, $2 \mathrm{~mm}$. Figure 7 shows the VSWR comparison. From the observation of Figure 6, the proposed antenna resonates at seven bands with good impedance matching. The Return loss $-10 \mathrm{~dB}$ bandwidths with corresponding resonances are listed in Table 2 with reflection coefficients and VSWR also noted in this table.

Table 2:-10db return loss bandwidth of the Sri Yantra antenna design

\begin{tabular}{|c|c|c|c|c|c|}
\hline $\begin{array}{l}\text { Multi- } \\
\text { band }\end{array}$ & $\begin{array}{c}\text { Impedance } \\
\text { Bandwidth (MHz }\end{array}$ & $\begin{array}{l}\text { Reflection } \\
\text { coeffi- cien }\end{array}$ & $\begin{array}{l}\text { Resonant } \\
\text { frequen- } \\
\text { cy }(\mathbf{G H z})\end{array}$ & VSW R & $\begin{array}{c}\text { Maxi- } \\
\text { mum } \\
\text { Gain }\end{array}$ \\
\hline$\overline{1}$ & $\begin{array}{l}3.99 \mathrm{GHz}- \\
4.09 \mathrm{GHz}=100\end{array}$ & $-23.74 \mathrm{~dB}$ & 4.04 & 1.139 & $4.613 \mathrm{~dB}$ \\
\hline 2 & $\begin{array}{l}4.92 \mathrm{GHz}- \\
4.98 \mathrm{GHz}=60\end{array}$ & $-12.53 \mathrm{~dB}$ & 4.94 & 1.618 & $2.718 \mathrm{~d} \mathrm{~B}$ \\
\hline 3 & $\begin{array}{l}5.81 \mathrm{GHz}- \\
5.99 \mathrm{GHz}=180\end{array}$ & $-12.38 \mathrm{~dB}$ & 5.88 & 1.632 & $4.771 \mathrm{~d} \mathrm{~B}$ \\
\hline 4 & $\begin{array}{l}6.55 \mathrm{GHZ}- \\
6.67 \mathrm{GHz}=120\end{array}$ & $-22.03 \mathrm{~dB}$ & 6.60 & 1.171 & $2.271 \mathrm{~d} \mathrm{~B}$ \\
\hline 5 & $\begin{array}{l}7.11 \mathrm{GHz}- \\
7.42 \mathrm{GHz}=310\end{array}$ & $-17.58 \mathrm{~dB}$ & 7.24 & 1.304 & $5.120 \mathrm{~d} \mathrm{~B}$ \\
\hline 6 & $\begin{array}{l}8.70 \mathrm{GHz}- \\
9.02 \mathrm{GHz}=320\end{array}$ & $-33.18 \mathrm{~dB}$ & 8.88 & 1.044 & $3.119 \mathrm{~d} \mathrm{~B}$ \\
\hline 7 & $\begin{array}{l}10.18 \mathrm{GHz}- \\
11.23 \mathrm{GHz}=1005\end{array}$ & $-18.70 \mathrm{~dB}$ & 10.92 & 1.262 & $3.473 \mathrm{~d} \mathrm{~B}$ \\
\hline
\end{tabular}

Table 3 presents the comparison of Sri Yantra design with the circular patch in terms of multiple bands along with and without DGS. In each case Sri Yantra design performs better than circular patch.

Table 3 Comparison of existed and proposed design

\begin{tabular}{ccc}
\hline & Circular patch & Sri Yantra \\
\hline Without DGS & Number of bands $=2$ & Number of bands $=5$ \\
With DGS & Number of bands $=5$ & Number of bands $=7$ \\
\hline
\end{tabular}

Simulated radiation patterns are depicted in Figure $8(\mathrm{a}-\mathrm{g})$ correspond XY-plane and XZ-plane which represents E-plane \& $\mathrm{H}$ - plane for resonant frequencies at $4.04 \mathrm{GHz}, 4.94 \mathrm{GHz}$,
$5.88 \mathrm{GHz}, 6.60 \mathrm{GHz}, 7.24 \mathrm{GHz}, 8.88 \mathrm{GHz}$ and $10.92 \mathrm{GHz}$.

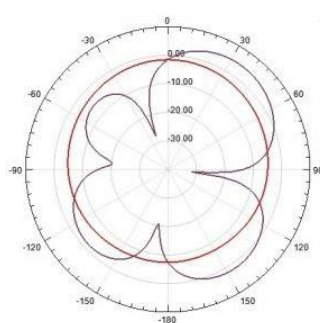

(a)

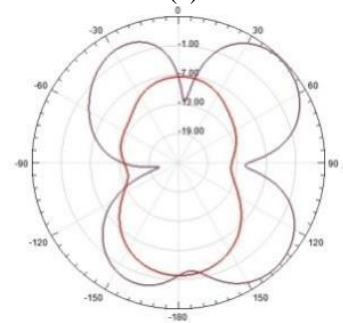

(c)

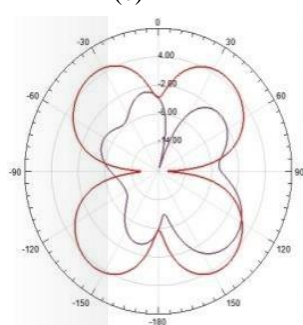

(e)

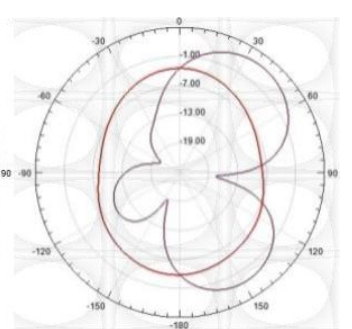

(b)

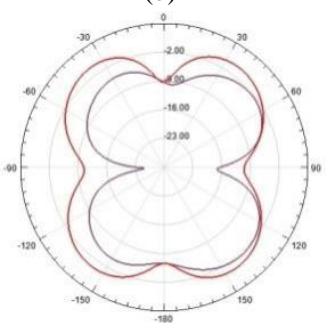

(d)

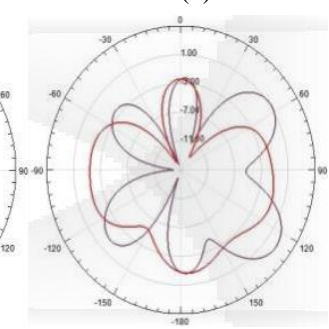

(f)

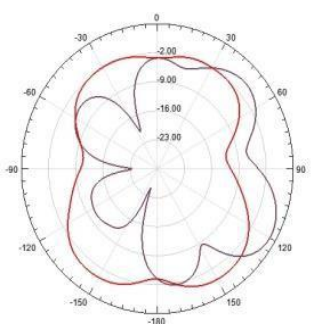

( g )

Fig. 8: Broad side 2D polar plots at a) $4.40 \mathrm{GHz}$ b) $4.94 \mathrm{GHz}$ c) $5.88 \mathrm{GHz}$ d) $6.60 \mathrm{GHz}$ e) $7.24 \mathrm{GHz}$ f) $8.88 \mathrm{GHz}$ g) $10.92 \mathrm{GHz}$ (red-E-plane \& black- $\mathrm{H}$ plane)

Figure 9 depicts the gain $v s$ frequency plot of the proposed antenna design.Table 3 Comparison of existed and proposed design

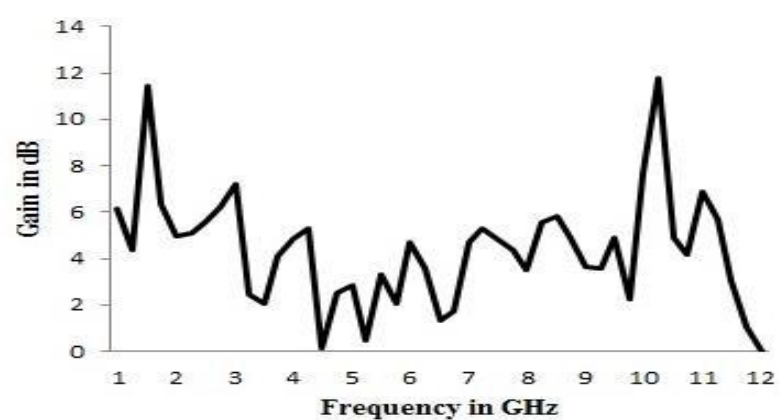

Fig. 9: Gain vs frequency plot of proposed antenna

Figure 10 (a-g) presents the magnitude of surface current distribution of the Sri Y antra design on both sides at intended resonant frequencies. It is evident that at outer edges of the patch contribute to radiation at lower frequencies while inner edges radiate at higher frequencies. 


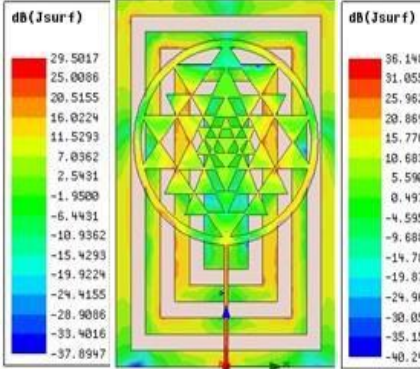

(a)

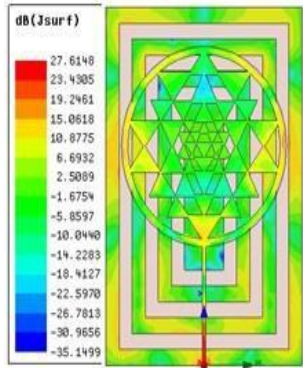

(c)

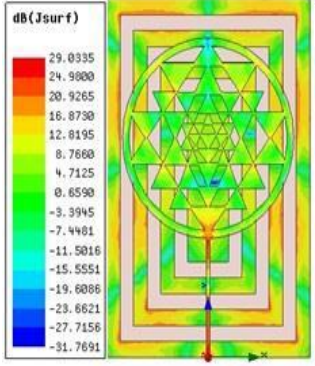

(e)

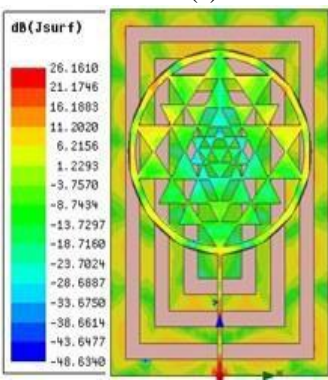

(g)

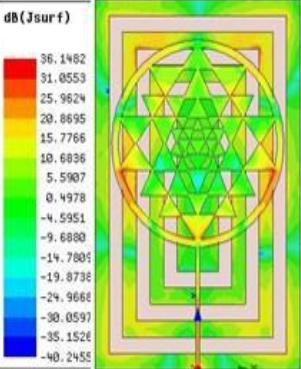

(b)

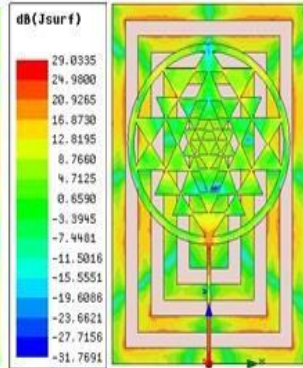

(d)

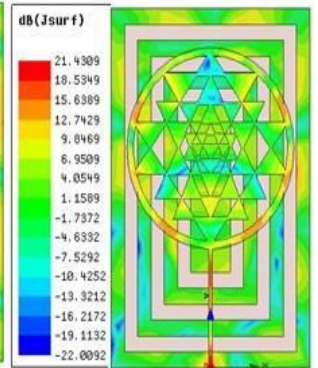

(f)
Fig. 10: Magnitude of surface current distribution at their corresponding resonant frequencies.

\section{Experimental authentication}

Figure 11 shows photographs of the prototype designed antenna. Measured and simulated results comparison of reflection coefficient and VSWR values of the proposed antenna are plotted in $\mathbf{F}$ igure $\mathbf{1 2}$ and $\mathbf{1 3}$.

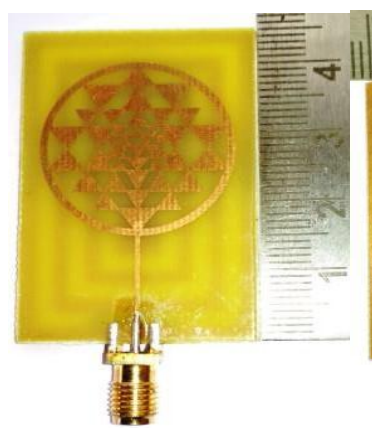

(a)

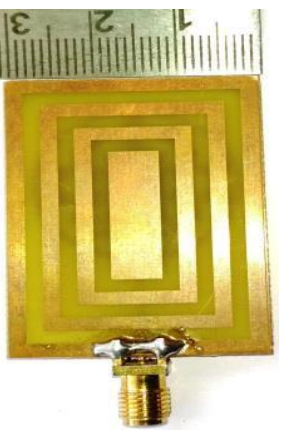

(b)
Fig. 11: Photographs of the proposed antenna a) top b) bottom view

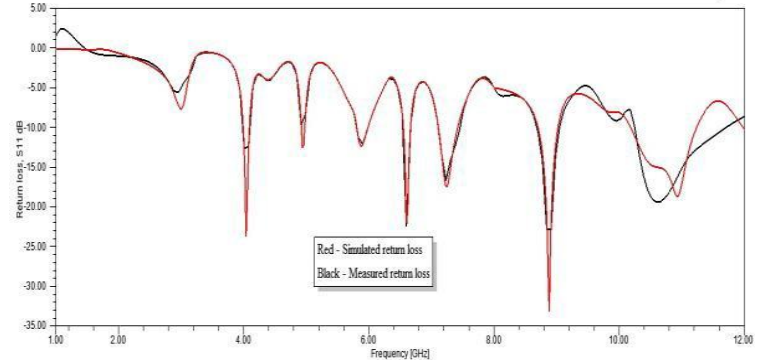

Fig. 12: Simulated and measured $S_{11}$ plot of proposed antenna

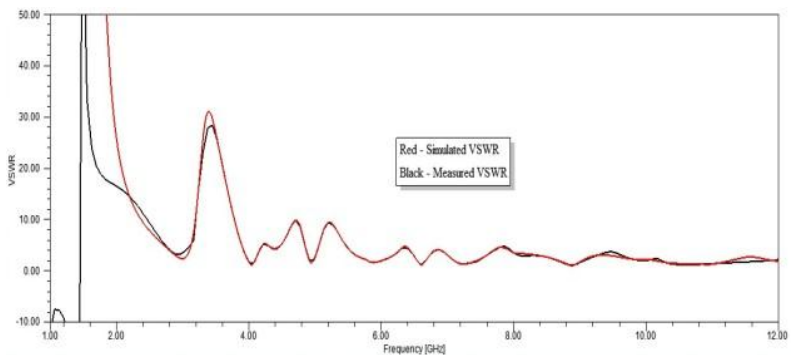

Fig. 13: Simulated and measured VSWR plot of proposed antenna

\section{Conclusion}

The combination of polygon slots and triangle fractal on the circular patch shows a sriyantra shaped design, which results seven resonant bands at $4.04 \mathrm{GHz}, 4.94 \mathrm{GHz}, 5.88 \mathrm{GHz}, 6.60 \mathrm{GHz}$, $7.24 \mathrm{GHz}, 8.88 \mathrm{GHz}$ and $10.92 \mathrm{GHz}$. In addition to the concentric rings in the ground structure improved peak gains are $4.613 \mathrm{~dB}$, $2.718 \mathrm{~dB}, 4.771 \mathrm{~dB}, 2.271 \mathrm{~dB}, 5.120 \mathrm{~dB}, 3.119 \mathrm{~dB}$ and $3.473 \mathrm{~dB}$ at their frequencies respectively. The proposed antenna design compared with various iterations and with and without DGS. The proposed antenna is usable for the wireless communication systems with improved bandwidth and gain especially working in the $\mathrm{C}$ $\& \mathrm{X}$ - bands. number here.

\section{References}

[1] Y.Tawk, K.Y.Kabalan, A.El-Hajj, C.G.Christodoulu, J.Costantine, "A Simple Multiband Printed Bowtie An- tenna", IEEE Antennas and Wireless Propagation Let- ters, Vol.7, 2008, https://sci-hub.tw/10.1109/LAWP.2008.2001027

[2] Manisha Gupta , Vinita Mathur , "Koch boundary on the square patch microstrip antenna for ultra wideband applications", Alexandria Engineering Journal, 2017, https://doi.org/10.1016/j.aej.2017.06.005

[3] M.E.Jalil, M.K.A.Rahim, N.A.Samsuri, N.A.Murad, H.A.Majid, K.Kamardin, M.A.Abdullah, "Fractal Koch Multiband Textile Antenna Performance with bending, WET conditions and on the Human Body", Progress in Electromagnetics Research Vol'140, 633-652, 2013, http://www.jpier.org/PIER/pier140/37.13041212.pdf

[4] Kapil Thakur, SumitKaushik, "Compact Design of H- shaped Fractal Microstrip Patch Antenna using different DGS for wireless Applications", International Journal of Innovative Research in Science, Engineering and Technology, Vol.3, Issue 10,October2014, http://www.rroij.com/openaccess/compact-design-of- hshaped-fractalmicrostrip-patchantenna-using- differentdgs-for-wireless-applications.pdf

[5] Yogesh kumar Choukikar, SatishK.Sharma, SantanuK.Behera, "Hybrid Fractal Shape Planar Monopole Antenna covering Multiband Wireless Communications with MIMO implementation for Handheld Mobile De- vices", IEEE Transactions on Antennas and Propaga- tion, Vol.62, No.3, March 2014, https://sci- hub.tw/10.1109/TAP.2013.2295213 
[6] Raj kumar, P.Malathi, "On the design of Wheel shaped fractal antenna", International Journal of Recent Trends in Engineering, Vol.2, No.6, November 2009, https://doi.org/10.1002/mop.25677

[7] L.H.Weng, Y.C. Guo, X.W.Shi and X.Q.Chen, "An Overview on Defected Ground Structure", Progress in Electromagnetics Research B, Vol.7, 173-189, 2008, http://www.jpier.org/PIERB/pier.php?paper=08031401

[8] Amandeep Singh, Surinder Singh. "A novel CPW-fed wideband printed monopole antenna with DGS" Interna- tional Journal of Electronics and Communications (AEÜ), Vol 69,
No
1
(2015),
pp.
299-306, http://dx.doi.org/10.1016/j.aeue.2014.09.016

[9] Alaknanda Kunwar, Anil Kumar Gautam, Karumudi Rambabu. "Design of a compact U-shaped slot triple band antenna for WLAN/WiMAX applications" " Inter- national Journal of Electronics and Communica- tions (AEÜ), Vol 71, January 2017, pp.82-88, https://doi.org/10.1016/j.aeue.2016.10.013.

[10] C.A.Balanis, Antenna Theory and Design, 3rd edition, MC Graw Hill publishing company, New Delhi, 843- 847, 2005.

[11] NamrataD.Mahajan, KunalN.Dekata, "Design and simu- lation of patch antenna for $3.51 \mathrm{GHz}$ S-band and Wi- MAX Application", International Conference on Ad- vances in Electrical, Electronics, Information, Commu- nication and BioInformatics, 2016, https://scihub.tw/10.1109/AEEICB.2016.7538382

[12] Jim \& James, Handbook of Microstrip Antenna, 135- 148 2009.

[13] Prateekchopra, MeghaBhandari, SanjeevSaxena, "Con- formal antenna using circular Microstrip Patches in C- band", 3rd International Conference on Signal Pro- cessing and Integrated Networks, 2016, https://scihub.tw/10.1109/SPIN.2016.7566801

[14] "How to draw an optimal Sri Yantra", Research center, http://www.sriyantraresearch.com/Construction/Optimal /how_to_draw.pdf

[15] Boltan and Macleod, "The geometry of the Sri Yantra Religion", 66-85, 1977, https://www.tandfonline.com/doi/abs/10.1016/0048$721 \mathrm{X} \% 2877 \% 2990008-2$

[16] "How to draw a Sri Yantra", Patrick Flanagan 1991, [17] https://youtu.be/6fYfFZ6EhFE 